\title{
The electronic origin of the ground state spectral features and excited state deactivation in cycloalkanones: the role of intermolecular H-bonding in neat and binary mixtures of solvents
}

\author{
Ibrahim Ahmed Z. Al-Ansari ${ }^{1}$
}

Received: 31 December 2018 / Accepted: 29 March 2019 / Published online: 26 April 2019

(C) The Author(s) 2019

\begin{abstract}
In this study, a D-A cycloalkanone (K1) has been investigated by steady state absorption and fluorescence in neat solvents and in three binary mixtures of nonpolar aprotic/polar protic, polar aprotic/polar protic, and polar protic/polar protic solvents. The experimental findings were complemented by density functional theory (DFT), time-dependent density functional theory (TDDFT), and NBO quantum-mechanical calculations. Experimentally, effective changes in absorption and fluorescence were observed by solute-solvent interaction. The binary K1-solvent 1 -solv 2 configuration, modeled at the B3LYP-DFT level, confirms involvement of inter-molecular $\mathrm{H}$-bonding with the carbonyl $\mathrm{C}=\mathrm{O}$ in the fluorescence deactivation process (quenching). This is supported by considerable electron delocalization from $\mathrm{C}=\mathrm{O}$ to the solvent's hydroxyl $\left(n_{\mathrm{O}} \rightarrow \sigma^{*} \mathrm{H}-\mathrm{O}\right)$. This type of hyperconjugation was found to be the main driver for solute-solvent stabilization.
\end{abstract}

Keywords DFT $\cdot$ TD-DFT $\cdot$ NBO $\cdot$ Cycloalkanones $\cdot$ Binary-mixture $\cdot$ Hyperconojugation

\section{Introduction}

Molecular $\pi$-systems with electron donating (D) and electron accepting (A) substituents generally are known as push-pull systems and characterized by intramolecular charge transfer (ICT) [1]. Such conjugated $\pi$-systems possess unique properties in both ground and excited states, due to D-A interaction that generates a new low-energy occupied molecular orbital (MO) with charge transfer character.

Compounds bearing a carbonyl $(\mathrm{C}=\mathrm{O})$ motif, such as in cycloalkanones, as an acceptor, have been a focus of intensive investigations, due to their biological activity, mainly, antiulcer, anticancer, antimitotic, antioxidant, anti-HIV, and antimalarial [2-5]. Further, the importance of such systems with the carbonyl substituents is known in many applications, such as optoelectron-

Electronic supplementary material The online version of this article (https://doi.org/10.1007/s00894-019-4015-6) contains supplementary material, which is available to authorized users.

Ibrahim Ahmed Z. Al-Ansari

iaalansari@gmail.com; i.a.alansari@qu.edu.qa

1 Department of Chemistry \& Earth Sciences, College of Arts \& Sciences - Qatar University, P.O. Box: 2713, Doha, Qatar ics [6-9] and as vibrational probe [10]. Moreover, the carbonyl $\mathrm{C}=\mathrm{O}$ chromophore is recognized as an important spectroscopic probe in studying intermolecular interactions by means of theoretical methods [11], transient optical [12], solid state ${ }^{17} \mathrm{O}$ NMR [13], UV [14], and IR spectroscopic techniques [10]. In medicinal chemistry, where the $\mathrm{C}=\mathrm{O}$ is common in many biological structures, it is understood that the oxygen acting as a hydrogen bond acceptor can interact with a binding site. This interaction is possible by two means: i) through dipole-dipole interaction, due to $\mathrm{C}=\mathrm{O}$ polarization, or ii) via hydrogen bonding (H-bonding) that involves the two lone-pair electrons of the oxygen $\mathrm{sp}^{2}$ hybridized orbital [15]. Moreover, recent studies based on fluorescence spectroscopy showed that cycloalkanones bind to BSA protein and DNA and the outcome of this interaction depends on their concentration $[16,17]$.

Our interest in these important biologically active cycloalkanones came due to the fact that the complete mechanism for their interaction with DNA and protein is still not completely understood $[16,17]$. Thus, in this work, we continue our investigation on one of the cycloalkanones we previously synthesized [18]. This push-pull compound with the carbonyl motif (denoted herein as K1), is built on a strong donor $N, N$ dimethyl-aniline unit (D) connected to the acceptor (A) cyclic benzoyl group, via a cyclic five-membered ring. 
In this study, the effects of the environment, through nonspecific interactions and $\mathrm{H}$-bonding, were considered in neat solvents and binary mixtures of some systems with different polarities and proticities. Binary mixtures are usually used to customize solvent properties in various chemical reactions. Thus, upon mixing, new solventsolute and solvent-solvent interactions, in many cases, lead to solvent properties different than neat solvents. Furthermore, in a binary mixture, many dynamic and static properties, such as viscosity, solubility, and polarizability among others, change with the variation in the composition of any of the constituents [19].

\section{Experimental details}

\section{Synthesis of the compound}

(3E(-2-\{[4-(N,N-dimethyl-amino)-phenyl]-methylene\}-2,3dihydro-1H-Inden-1-one (K1) (Chart 1). The complete procedure for the synthesis and characterization of the title compound are given in our earlier work [18]. All solvents used in this study were of spectroscopic grades and purchased from Fluka Chemical Co. and used as received.

\section{Spectroscopic techniques}

The steady state electronic absorption (using $1 \mathrm{~cm}$ matched quartz cells) and fluorescence spectra were recorded at room temperature. Absorption spectra was recorded with Perkin Elmer diode array UV/Vis, while emission spectra were taken with Shimatzu RF-500 spectrometer. Emission spectra were obtained using a small angle $\left(90^{\circ}\right)$ front surface excitation geometry. The slit width was $5 \mathrm{~nm}$ for both excitation and emission. The concentration of the compound in all neat and mixed solvents was $1.0 \times 10^{-5}$ and $1.0 \times 10^{-6} \mathrm{M}$ for absorption and emission measurements, respectively. Fresh solutions were used for all measurements, and emission spectra were not corrected for the spectral response of the instruments. The samples of compound $\mathbf{K} \mathbf{1}$ in the binary mixtures were prepared at different solvents ratios (fixed solute concentration).

\section{Computational methods}

Density functional theory (DFT) has been used for geometry optimizations of the isolated molecules and the hydrogen-bonded solute-solvent complexes. For this purpose, the three-parameter B3LYP density functional including the Becke's gradient exchange corrections [20] and the Lee-Yang-Parr correlations functions [21] were used. The $6-31 \mathrm{G}(\mathrm{d}, \mathrm{p})$ and $6-31+\mathrm{G}(\mathrm{d}, \mathrm{p})$ [22] were chosen as the basis sets throughout. Here, B3LYP is applied owing to its typically excellent performance in the prediction of geometries and vibrational frequencies for simple organic molecules. Also, the choice of $6-31 \mathrm{G}+(\mathrm{d}, \mathrm{p})$ is justified by many studies on similar systems, which have shown that this atomic basis set is sufficient for geometries of both ground and excited states [23, 24, 25]. No restrictions were imposed on the geometry optimization. All calculated minima were verified by frequency calculations; no imaginary frequencies were found. Implicit solvent effects were considered using a modified version of the conductor-like polarizable continuum model (CPCM [26]. Single point energies for the un-relaxed compound K1 or solvent(s) were carried out at the same level of functional and basis set throughout. Default parameters were used for the PCM cavity, and acetonitrile (ACN) and methanol $(\mathrm{MeOH})$ were used as media. Solvation through specific solvent effects were conducted using one or two solvent molecules $\mathrm{H}$-bonded to the $\mathrm{C}=\mathrm{O}$ of the carboxyl group in the same plane.

The electronic excitation energies as well as the oscillation strengths of the low-lying singlets and triplets electronically excited states were calculated using time-dependent analytical gradients (TD-DFT) [27], with the B3LYP functional (TDB3LYP) and the $6-31+\mathrm{G}(\mathrm{d}, \mathrm{p})$ basis set.

The donor $(i)$ and acceptor $(j)$ electronic interactions were acquired from the natural bond orbital (NBO) analysis, using the second order perturbation energies $E_{i-j}^{(2)}$ of orbital interactions from the filled (lone pair) Lewis type NBO to another neighboring electron deficient orbital (non-Lewis type) $\sigma^{*}$ antibonding. These NBO charge analysis were performed at the B3LYP/6-31+G(d,p) level of theory [28], on the optimized structures in the gas phase and solution (C-PCM) alike. The stabilization energy, $\left(E_{i-j}^{(2)}\right)$, for each NBO(i) and acceptor (j) is generally estimated by the second-order perturbation theory $[29,30$, 31] according to:

$E_{i=j}^{(2)}=\Delta E_{i j}=q_{i} \frac{F(i, j)^{2}}{\varepsilon_{i}-\varepsilon_{i}}$

where $q_{\mathrm{i}}$ is the donor orbital occupancy, ${ }_{i}$ and ${ }_{j}$ are diagonal elements (orbital energies), and $F(i, j)^{2}$ is the off-diagonal NBO Fock-matrix element. The NBO-6 program [32], implemented in the Gaussian 16 package [33], was used for this purpose. All computations, were performed by imposing no symmetry restrictions $\left(\mathrm{C}_{\mathrm{i}}\right.$ point group). All calculations were performed with the latest version of Gaussian 16 program [33], and molecular orbitals visualization were carried out by Gauss View V6.0 [34]. 


\section{Results and discussion}

\section{Steady state absorption and emission}

\section{Comparison of absorption and fluorescence in nonpolar cyclohexane (CHX)}

The complete ground state absorption and excited state emission results were given in our earlier work [18]. Here, we only give general features of the electronic absorption and emission. The first transition (long wavelength, LW) in this compound was observed at $402 \mathrm{~nm}$ in cyclohexane (CHX) and at $432 \mathrm{~nm}$ in methanol. In cyclohexane, a shoulder also appears at $\sim 40 \mathrm{~nm}$, and a weak absorption with vibrational feature appears at $\sim 300-340 \mathrm{~nm}$. Fluorescence maxima $\left(\widetilde{\nu}_{f}^{\max }\right)$ on the other hand, are slightly red-shifted in $\mathrm{CHX}$ and found at $420 \mathrm{~nm}$.

This molecule shows a mirror image of absorption and emission, indicating no structural change (planar structure) in the excited state. With regard to the Stokes shift (cf. Fig. 1a and Fig. S1a), compound K1 exhibits a moderate shift of $1066 \mathrm{~cm}^{-1}(\sim 0.13 \mathrm{eV})$ in CHX. Our TD-DFT calculations (as will be outlined in the coming section 3.2), show that the origin of the LW band is $\mathrm{S}_{0} \rightarrow \mathrm{S}_{1}{ }^{1}\left(\pi, \pi^{*}\right)$, whereas the weak band in the middle region of $300-340 \mathrm{~nm}$ is due to $S_{0} \rightarrow S_{3}$ transition and possess a ${ }^{1}\left(n, \pi^{*}\right)$ signature. The $\mathrm{S}_{0} \rightarrow \mathrm{S}_{2}$ transition is not seen since it is dark (cf. Tables 1 and 2).

\section{Absorption in nonpolar/polar protic $(\mathrm{CHX} / \mathrm{MeOH})$ binary mixture}

The effect of H-bonding between the solvent and the carbonyl motif $(\mathrm{C}=\mathrm{O})$ of these compounds was studied in a nonpolar/ polar protic system, mainly cyclohexane-methanol by titration of $\mathrm{K} 1$ in cyclohexane (CHX) solution with increasing the fraction of methanol in the mixture while keeping the solute at constant concentration. As first observation, Fig. 1a shows the absorption of $\mathrm{K} 1$ in $\mathrm{CHX}$ with increasing $\mathrm{MeOH}$ ratio, while the normalized spectra of the same are given in Fig. 1b. Notably, the addition of a small amount of methanol causes a drop in intensity with peak red-shifted. We observe a slight loss of the vibrational feature seen in pure cyclohexane due to $\mathrm{S}_{0} \rightarrow \mathrm{S}_{1}$ transition (assigned based on TD-DFT calculations, for more information see ref. [18]) with addition of a small quantity of $\mathrm{MeOH}$. As the percentage of $\mathrm{MeOH}$ increases, the spectra become structureless and broadened. This occurs owing to site specific interaction of the acidic proton of $\mathrm{MeOH}$ with the basic carbonyl $\mathrm{C}=\mathrm{O}$. The decrease in intensity is explained by our TD-DFT calculation (full details will be given shortly), where TD-DFT calculation show that the lowest absorption band $\left(\mathrm{S}_{0} \rightarrow \mathrm{S}_{1}\right.$ transition) in neat cyclohexane has an oscillator strength of ca. $f=0.855$, whereas in $\mathrm{MeOH}$ solution (C-PCM solvation model) it is ca. $f=0.836$, and further decreases to 0.632 in the $\mathrm{K} 1$ $\mathrm{MeOH}$ complex, where one methanol molecule is H-bonded to the carbonyl $\mathrm{C}=\mathrm{O}$ motif. Furthermore, the red-shift of the low-energy band is evident in Fig. 2, where $S_{1}$ state energy drops with the increase in solvent bulk polarity due to better stabilization of the K1-solvent complex by association of the solute with methanol molecules by H-bonding.

\section{Absorption in polar aprotic/polar protic (ACN-MeOH) and protic/protic $\left(\mathrm{MeOH}-\mathrm{H}_{2} \mathrm{O}\right)$ binary mixtures}

To complement our understanding of the role of H-bonding on the spectral features of these molecules in the ground state, we carried out absorption titration of compound $\mathrm{K} 1$ in two more binary solvent systems. The first solvent system was composed of a polar aprotic and polar protic solvents (acetonitrile/methanol) mixture, and the other system consists of both polar protic solvents (methanol/water). Figures 3 and 4, show the normalized steady state absorption spectra of these two binary systems, while the titrated spectra are given in Fig. S1a and Fig. S1b (supporting information). We notice that, in both mixtures, the band assigned to $\mathrm{S}_{0} \rightarrow \mathrm{S}_{3}$ transition has almost vanished. However, in the ACN-MeOH mixture, the intensity of the LW band maxima remains relatively unchanged with slight red-shift as the fraction of methanol in the mixture is increased. Further, this band shows a clear broadening with parallel band maxima shift toward lower energy, apparently due to stronger interactions with methanol, which leads to stabilization of the ground state complex. However, the short wavelength at $\sim 300-340 \mathrm{~nm}$ (SW) band shows a noticeable decrease in intensity with no change in band position (cf. Fig. 3).

The situation in the $\mathrm{K} 1-\mathrm{MeOH}-\mathrm{H}_{2} \mathrm{O}$ system is quite different, as shown in Fig. 4. Initially, the LW band drops slowly with progressive shift toward lower energy, following increasing water content till 50\% mixture reached. Further increase in the proportion of water results in loosing intensity with no change in position of peak maxima. However, the LW band becomes broader as the fraction of water increased. Moreover, the band intensity drop is noticeable in the SW band as well, though the decrease is steadier than seen in the LW band case.

\section{Structural and electronic features at the ground state}

The optimization energies of the title compound $\mathrm{K} 1$ in the gas phase, $\mathrm{CHX}, \mathrm{ACN}$, and $\mathrm{MeOH}$ as calculated by the CPCMDFT method, are collected in Table 1 and 2. The effect of stabilization of solvation by solvent polarity is obvious, and stability increases in the order: gas phase $<\mathrm{CHX}<\mathrm{MeOH}=$ $\mathrm{ACN}$. Further, we noticed a slight increase in the dipole moment from the nonpolar $\mathrm{CHX}$ to the polar $\mathrm{MeOH}$ or $\mathrm{ACN}$. 
Fig. 1 (a) Absorption spectra of compound $\mathbf{K 1}\left(\mathrm{c}=1 \times 10^{-5}\right)$ in cyclohexane-methanol binary mixture (The ratios are: $\mathrm{CHX} /$ $\mathrm{MeOH}, 100: 0,95: 5,60: 40,40: 60$, 20:80\%). Arrows indicates increasing $\mathrm{MeOH}$ portion. (b) The normalized spectra of the same
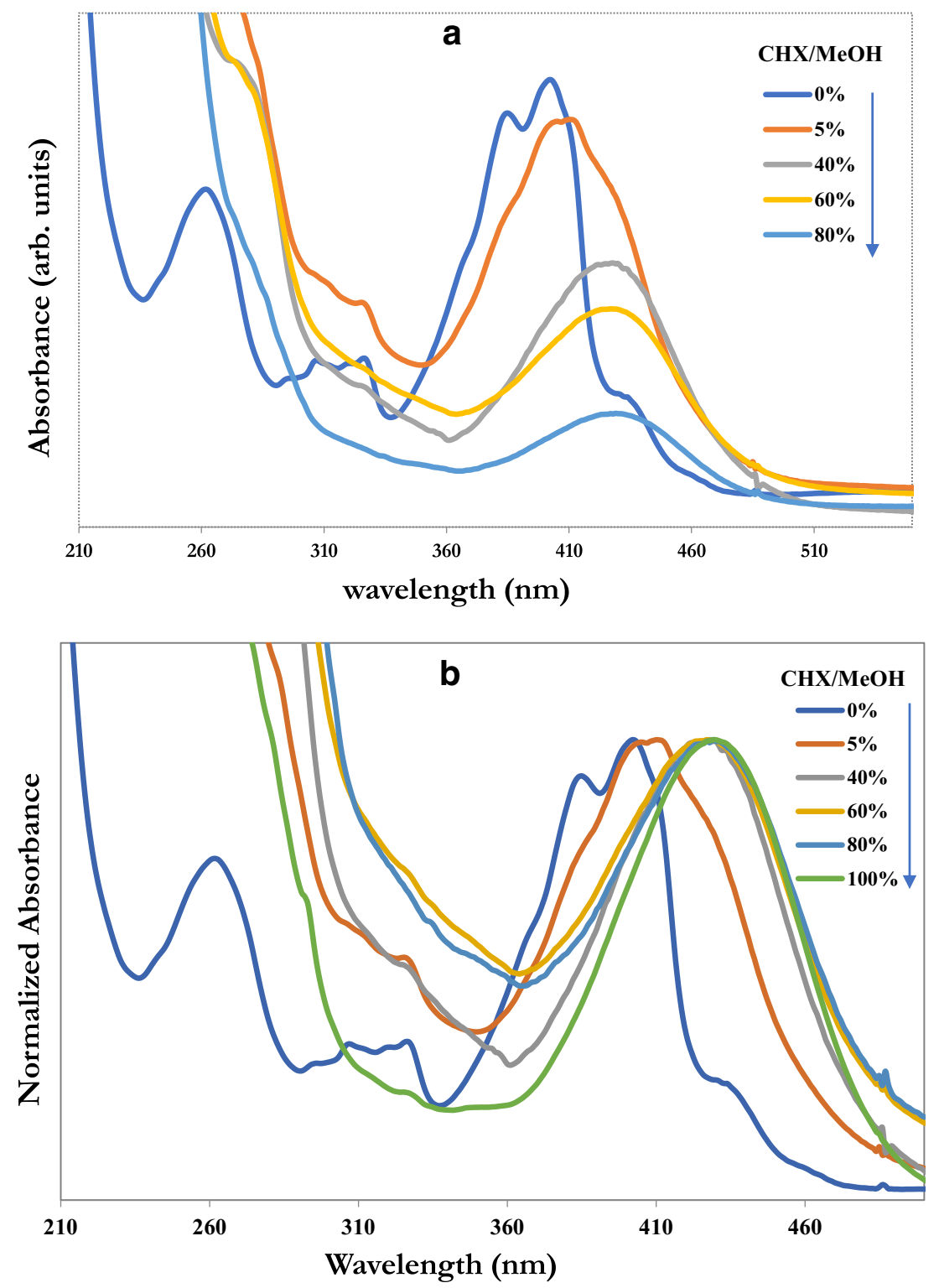

With regard to the orbitals involved in the vertical electronic transitions in this compound, the calculated TD-DFT calculations in the gas phase show that the transition HOMO- $\rightarrow$ LUMO+1 constitutes the major contribution to the $S_{2}$ state. The HOMO-1 is localized on the carbonyl oxygen (in-plane) and the LUMO+1, is delocalized on the two phenyl rings with neither electron density on the carbonyl nor dimethyl-amine motifs. In the gas phase, $\mathrm{S}_{2}$ state has a $n \rightarrow *$ character and is

Table 1 Ground state minimum energy ${ }^{a}$ of compound $\mathbf{K} \mathbf{1}$ in some selected solvents

\begin{tabular}{lll}
\hline Cyclohexane $(\mu)^{\mathrm{b}}$ & Acetonitrile & Methanol \\
\hline$-826.185897(8.59)$ & $-826.193830 .(10.8)$ & $-826.193778(10.8)$
\end{tabular}

${ }^{a}$ Calculated at B3LYP-CPCM/6-31G+(d,p), in a.u. ${ }^{b}$ dipole moment in debye (D) not emissive $(f=0.000)$, whereas $\mathrm{S}_{1}{ }^{1}\left(\pi, \pi^{*}\right)$ is an emissive bright state $(f=0.7182)$ that originates from HOMO $\rightarrow$ LUMO transition and possesses considerable intramolecular charge transfer character (ICT) from the donor dimethyl aniline to the rest of the molecule (see our earlier work inreference 18).

Table 2 Calculated excitation energies ( $\lambda$, in $\mathrm{nm}$ ), oscillator strength $(f)$ and orbital compositions $(c)$ for the three first $\mathrm{S}_{0} \rightarrow \mathrm{S}_{\mathrm{n}}(\mathrm{FC})$ vertical transitions of compounds $\mathbf{K 1}$, calculated in the gas phase at B3LYP/6$31+\mathrm{G}(d, p)$ level

\begin{tabular}{lllll}
\hline State & $(\mathrm{eV})$ & $f$ & $c$ & Excitation \\
\hline $\mathrm{S}_{1}$ & $389(3.188)$ & 0.718 & 0.703 & $70 \rightarrow 71$ \\
$\mathrm{~S}_{2}$ & $381(3.25)$ & 0.000 & 0.699 & $69 \rightarrow 71$ \\
$\mathrm{~S}_{3}$ & $292(4.24)$ & 0.028 & 0.541 & $70 \rightarrow 72$ \\
& & & 0.223 & $68 \rightarrow 71$ \\
\hline
\end{tabular}


Fig. 2 State energies (vertical transitions) for compound $\mathbf{K} \mathbf{1}$ in the gas phase, cyclohexane (CHX), acetonitrile ( $\mathrm{ACN})$, and $\mathrm{K} 1-\mathrm{MeOH}$-cluster, calculated at PCM-TD-DFT/B3LYP/6-31+ $\mathrm{G}(\mathrm{d}, \mathrm{p})$ and at TD-DFT/B3LYP/6$31+\mathrm{G}(\mathrm{d}, \mathrm{p})$ for the cluster

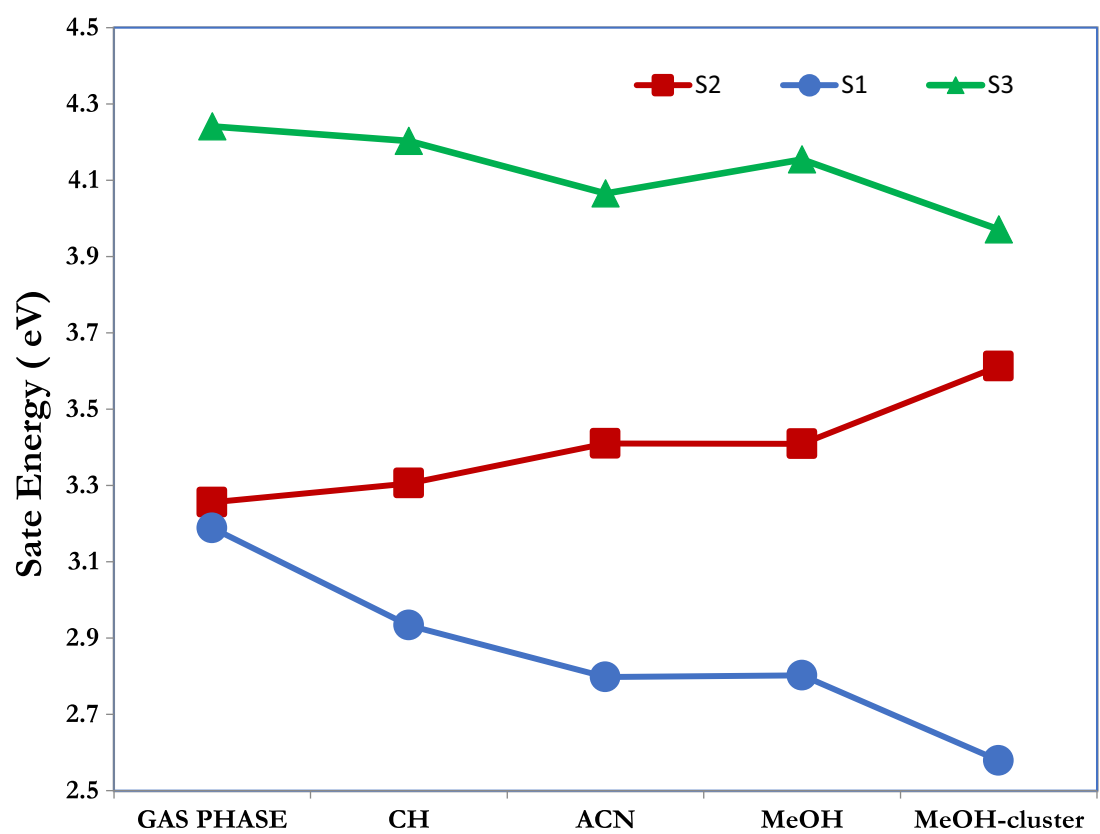

We plotted the energies of the MO orbitals involved in the electronic transitions in these solvents, and we noticed that $\mathrm{LUMO}+1$ is not sensitive to the solvents type (no change) as the electron density surfaces calculations show that no electron density is found on the carbonyl motif, thus excluding any effects of solvent's acidity on the spectral changes, due to specific solvent-solute interaction at this site. HOMO MOs are also seen to be insensitive to solvent polarity. However, HOMO-1 and LUMO MOs are stabilized in the order: gas phase $<\mathrm{CHX}<\mathrm{ACN}<\mathrm{MeOH}$. The higher stability in the protic solvent $\mathrm{MeOH}$ reflects the site-specific interaction between the electron rich carbonyl oxygen and the solvent.

The calculated excitation energies for $\mathrm{K} 1$, in bulk solvation using the C-PCM model, show that the position of the transition $\mathrm{S}_{0} \rightarrow \mathrm{S}_{1} \tilde{\nu}_{a b s}^{\max }$, is bathochromically shifted compared to gas phase, whereas that of $S_{0} \rightarrow S_{2}$ is hypsochromically shifted (cf. Fig. 2). The shift of $S_{1}$ state to lower-energy with the solvent change from the gas phase to $\mathrm{MeOH}$ is in accord with the experimentally measured maxima in $\mathrm{CHX}-\mathrm{MeOH}$ binary mixture, where the band maxima is shifted to lower
Fig. 3 Normalized absorption spectra of compound $\mathbf{K} \mathbf{1}$ in nonhydrogen-bonding acetonitrile and hydrogen-bonding methanol solvation environment. A:M represents acetonitrile-methanol $(\mathrm{ACN}-\mathrm{MeOH})$ solution $(v / \mathrm{v})$

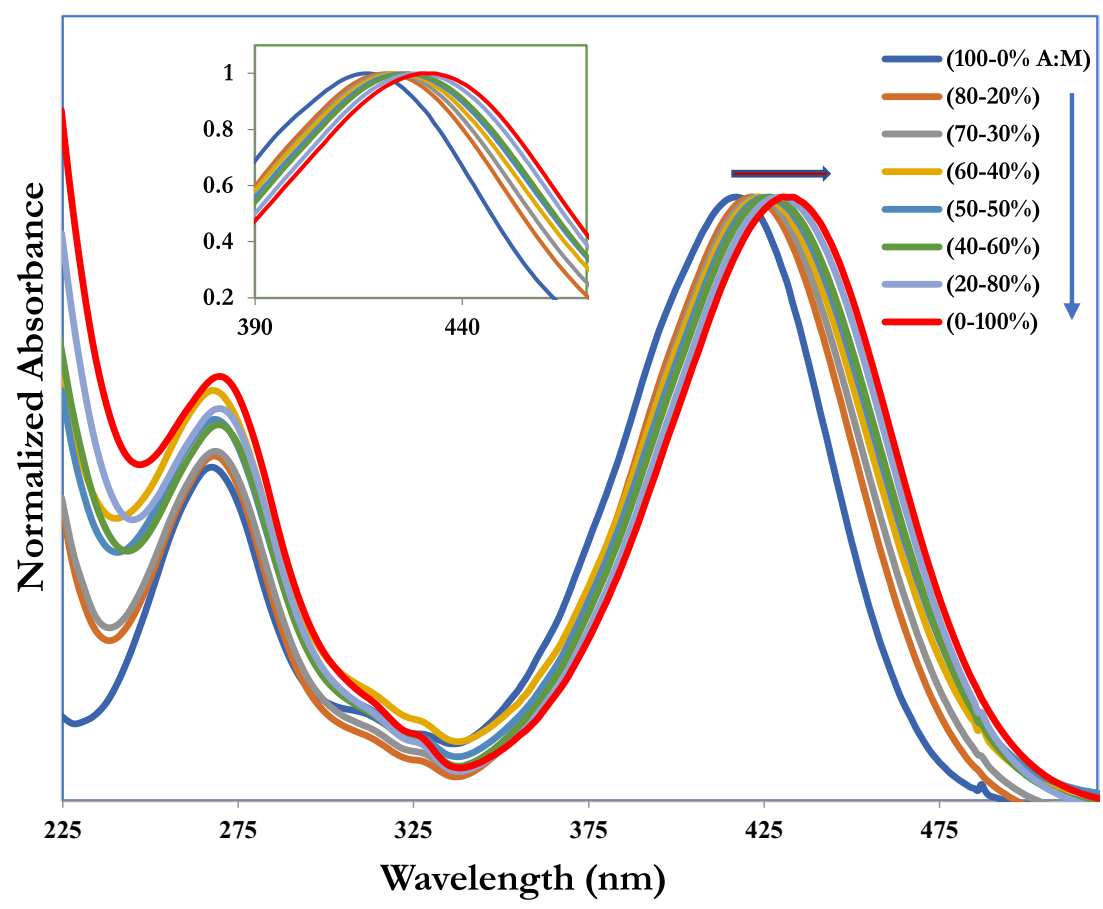


Fig. 4 Normalized Absorption spectra of compound $\mathbf{K} \mathbf{1}$ in hydrogen-bonding methanol and water solvation environment. $\mathrm{M}$ : W represents Methanol-Water $\left(\mathrm{MeOH}-\mathrm{H}_{2} \mathrm{O}\right)$ solution $(\mathrm{v} / \mathrm{v})$

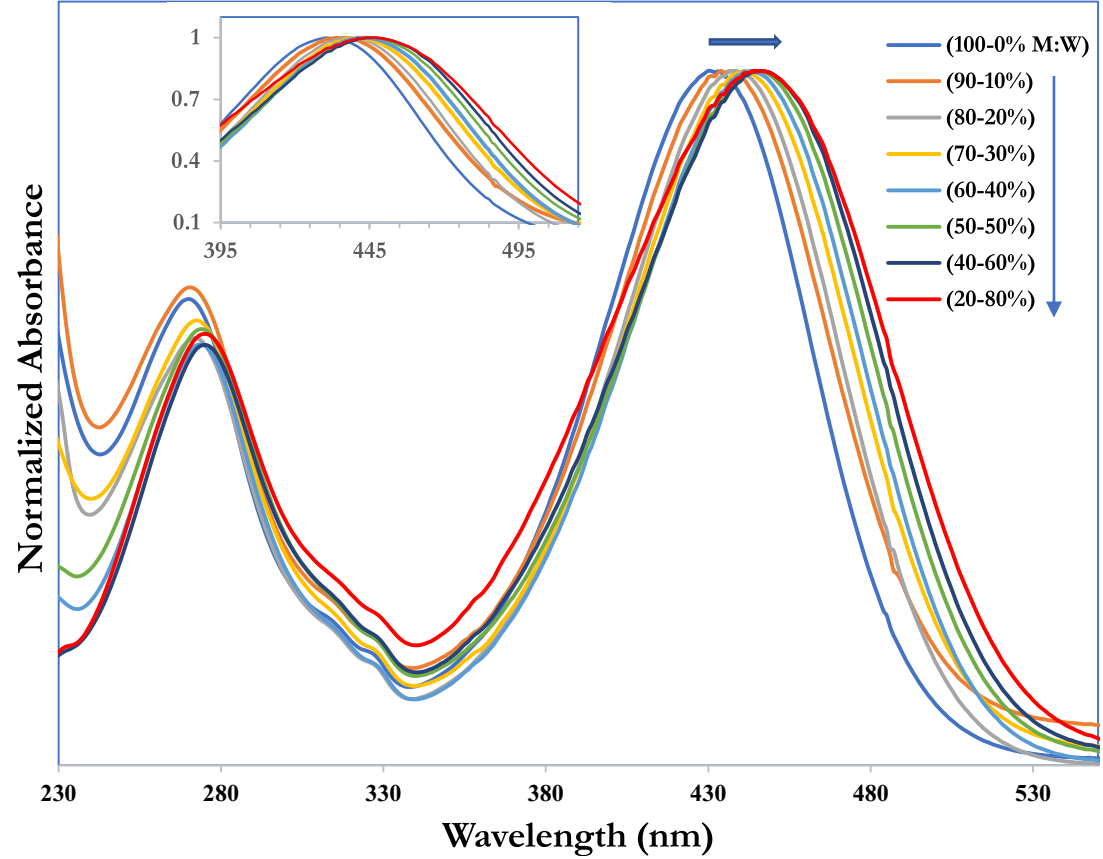

energy with substantial drop in intensity (cf. Figures $1 \mathrm{a}$ and $\mathrm{b}$ ). The explanation for this, is that $\mathrm{S}_{0} \rightarrow \mathrm{S}_{1}$ is a ${ }^{1}\left(\pi, \pi^{*}\right)$ in nature, with charge transfer from dimethylaniline to the $\mathrm{C}=\mathrm{O}$ moiety, which will facilitate solute-solvent interaction through $\mathrm{H}$ bonding, causing stabilization to this state.

In Fig. 2, we included the result of our calculations modeling for the complexation of the carbonyl $\mathrm{C}=\mathrm{O}$ with a single methanol molecule $(\mathrm{K} 1-\mathrm{MeOH})$ calculated in the gas phase, to gain a better conclusion of the specific solute-solvent interaction. We notice a substantial increase in the $S_{2}-S_{1}$ and decrease in $\mathrm{S}_{3}-\mathrm{S}_{1}$ energy gaps for this structure, compared to the $\mathrm{C}-\mathrm{PCM}$ solvation method. We believe that this occurs owing to strong H-bonding between $\mathrm{K} 1$ and the $\mathrm{MeOH}$ molecule, which has a profound effect on the position of both $\mathrm{S}_{1}{ }^{1}\left(\pi, \pi^{*}\right)$ and $\mathrm{S}_{2}{ }^{1}\left(n, \pi^{*}\right)$ states.

Inspection of Fig. 2 reveals that the effect of ACN is comparable to $\mathrm{MeOH}$ due to their close polarity $\left(\varepsilon_{\varepsilon \mathrm{ACN}}=37.5\right.$ and $\varepsilon \mathrm{MeOH}=32.7)$. We notice that the $\mathrm{S}_{2} / \mathrm{S}_{1}$ energy gap $\left(\Delta \mathrm{E}\left(\mathrm{S}_{2}-\mathrm{S}_{1}\right)\right)$ is in the order: gas phase $(0.0677 \mathrm{eV})<\mathrm{CHX}(0.353 \mathrm{eV})<\mathrm{ACN}$ $(0.599 \mathrm{eV})<\mathrm{MeOH}(0.618 \mathrm{eV})$, while the same order is found for the $\mathrm{S}_{3} / \mathrm{S}_{1}$ gap $(1.0534 \mathrm{eV}, 1.2125 \mathrm{eV}, 1.2557 \mathrm{eV}$, and $1.2911 \mathrm{eV}$, respectively). This increasing trend is in qualitative agreement with the experimentally measured values in these solvents, which show that the $\mathrm{S}_{3}-\mathrm{S}_{1}$ energy separations are $5959.9 \mathrm{~cm}^{-1}(0.74 \mathrm{eV}), 6788.6 \mathrm{~cm}^{-1}(0.84 \mathrm{eV})$, and $7621.3 \mathrm{~cm}^{-1}(0.94 \mathrm{eV})$ in $\mathrm{CHX}, \mathrm{ACN}$, and $\mathrm{MeOH}$, respectively.

The increase in the $\mathrm{S}_{2}-\mathrm{S}_{1}$ energy separation (Table 3), as our calculations show, is a result of destabilization of the $\mathrm{S}_{2}$ state, along with stabilization of the $\mathrm{S}_{1}$ state. Since the $\mathrm{S}_{2}$ state is mainly a HOMO-1 $\rightarrow$ LUMO transition, which possesses a $n \rightarrow \pi^{*}$ character, interaction of the carbonyl- oxygen through $\mathrm{H}$-bonding (as in $\mathrm{MeOH}$ ) stabilizes HOMO-1 as well as LUMO and LUMO+1 (cf. Fig. S2), while HOMO is not changed. Thus, the separation between HOMO-1/LUMO orbitals is reflected in the $\Delta E_{\mathrm{S} 2 / \mathrm{S} 1}$ gap (Fig. 2). This blue-shift in the $n, \pi^{*}$ transition has been a subject of many studies from both theoretical and experimental points of view. It is generally accepted now that change in $\mathrm{C}=\mathrm{O} \cdots$ solvent $\mathrm{H}$-bond strength upon excitation causes the solvatochromic blue-shift in $\mathrm{C}=\mathrm{O} n, \pi *$ transition $[35,36]$. On the basis of direct field (DRF) calculations, it has been postulated that this blue-shift is attributed to ground state electrostatics of the carbonyl H-bond [37]. Such argument, recently, has found support in the IR study on a range of different compounds with $\mathrm{C}=\mathrm{O}$ functionalities [38], where the $n, \pi^{*}$ shifts showed linear sensitivity to calculated electrostatic fields on carbonyls.

Using the CPCM model of solvation, we noticed along with the increase in the $\mathrm{S}_{2}-\mathrm{S}_{1}$ gap (cf., Table $\mathrm{S} 2$ in the supporting information) a slight decrease in the intensity of $\mathrm{S}_{0} \rightarrow \mathrm{S}_{1}$ absorption from cyclohexane $(f=0.855)$ to methanol $(0.836)$. On the other hand, the $\Delta E_{\mathrm{S} 3-\mathrm{S} 1}$ increases in the order gas phase $(1.0534)<\mathrm{CHX}(1.2125)<\mathrm{ACN}(1.2557)<1.2911(\mathrm{MeOH})$ (cf. Table 3). However, no changes were noticed in the (ca., $\sim f=0.03$ ) for the $\mathrm{S}_{0} \rightarrow \mathrm{S}_{3}$ electronic transitions coefficients.

It is generally accepted that the effect of $\mathrm{H}$-bonding cannot be properly described by the polarizable continuum model (PCM) of the media. Therefore, in this study, the effects of specific solvation in the solute-solvent and solute-solvents binary mixture have been accounted for and simulated considering a composition of compound $\mathrm{K} 1$ and one or two solvents bound to the carbonyl oxygen. 
Table 3 State energies and oscillator strength $(f)$ of compound K1 and K1-solvent complex, calculated in the gas phase at TD-DFT-B3LYP/6-31+ $\mathrm{G}(\mathrm{d}, \mathrm{p})$ and C-PCM-TD-DFT-B3LYP/6-31+G(d,p)

\begin{tabular}{|c|c|c|c|c|c|c|}
\hline \multirow[t]{2}{*}{ Structure } & \multicolumn{3}{|c|}{ State energy ${ }^{a}(f)^{b}$} & \multirow[t]{2}{*}{$\Delta \mathrm{E}\left(\mathrm{S}_{1} / \mathrm{T}_{1}\right)$} & \multirow[t]{2}{*}{$\Delta \mathrm{E}\left(\mathrm{S}_{2} / \mathrm{S}_{1}\right)$} & \multirow[t]{2}{*}{$\Delta \mathrm{E}\left(\mathrm{S}_{3} / \mathrm{S}_{1}\right)$} \\
\hline & $\mathrm{S}_{1}$ & $\mathrm{~S}_{2}$ & $\mathrm{~T}_{1}$ & & & \\
\hline K1(gas phase) & $3.1882(0.7182)$ & $3.2559(0.0000)$ & 2.2236 & 0.0677 & 0.0677 & 1.0534 \\
\hline $\mathrm{K} 1(\mathrm{CHX})^{c}$ & $2.9906(0.8555)$ & $3.3441(0.0000)$ & 2.1688 & 0.8218 & 0.3530 & 1.2125 \\
\hline $\mathrm{K} 1(\mathrm{ACN})^{c}$ & $2.8094(0.9464)$ & $3.4081(0.0000)$ & 1.9262 & 0.8832 & 0.5987 & 1.2557 \\
\hline $\mathrm{K} 1(\mathrm{MeOH})^{c}$ & $2.8639(0.8367)$ & $3.4819(0.0000)$ & 2.0674 & 0.7965 & 0.6180 & 1.2911 \\
\hline $\mathrm{K} 1-\mathrm{ACN}^{d}$ & $3.0270(0.743)$ & $3.3435(0.0000)$ & 2.0475 & 0.9795 & 0.3165 & 1.1157 \\
\hline $\mathrm{K} 1-\mathrm{MeOH}^{d}$ & $2.8516(0.632)$ & $3.4805(0.0001)$ & 2.1008 & 0.9262 & 0.6289 & 1.1933 \\
\hline $\mathrm{K} 1-\mathrm{H}_{2} \mathrm{O}^{d}$ & $3.0481(0.788)$ & $3.4391(0.0000)$ & 2.0565 & 0.9916 & 0.3910 & 0.4770 \\
\hline $\mathrm{K} 1-\mathrm{ACN}-\mathrm{MeOH}^{d}$ & $2.9728(0.742)$ & $3.3674(0.0011)$ & 2.0038 & 0.9690 & 0.3946 & 1.1313 \\
\hline $\mathrm{K} 1-\mathrm{MeOH}-\mathrm{H}_{2} \mathrm{O}^{d}$ & $2.9864(0.786)$ & $3.4322(0.0000)$ & 2.0319 & 0.9079 & 0.5225 & 0.4625 \\
\hline
\end{tabular}

${ }^{\mathrm{a}}$ in $e V .{ }^{b}$ oscillator strength $(f) .{ }^{c}$ calculated by the CPCM solvation method at the same level of theory

${ }^{\mathrm{d}}$ for the K1-solvent complex calculated in the gas phase at TD-DFT-B3LYP/6-31+G(d,p)

The above findings were complemented by NBO theoretical calculations, where we calculated the stabilization energies through hyperconjugation associated with complexation between $\mathrm{K} 1$ and one solvent molecule explicitly H-bonded to the in-plane carbonyl lone pair (cf. Figure S3), or two solvents, where the second one intermolecularly $\mathrm{H}$-bonded to the first solvent. The analyses were carried out by examining all possible interactions from the donor carbonyl oxygen lonepair to the empty $\sigma^{*}$ hydroxyl $\mathrm{O}-\mathrm{H}$ or $\mathrm{C}-\mathrm{H}$ of the solvent.

In the $\mathrm{K} 1-\mathrm{MeOH}$, we noticed a considerable charge transfer ca. $16.71 \mathrm{kcal} \mathrm{mol}^{-1}$ from $\operatorname{lp}(1) n_{\mathrm{C}=\mathrm{O}}$ and $18.23 \mathrm{kcal} \mathrm{mol}^{-1}$ from $\operatorname{lp}(2) n_{\mathrm{C}=\mathrm{O}}$ to $\sigma^{*} \mathrm{O}-\mathrm{H}$ of the alcohol molecule. This is to be compared to only $3.80 \mathrm{kcal} \mathrm{mol}^{-1}$ conjugation in the K1-ACN complex. Furthermore, in the $\mathrm{K} 1-\mathrm{ACN}-\mathrm{MeOH}$ these hyperconjugation energies reduce to 3.84 and $2.05 \mathrm{kcal} \mathrm{mol}^{-1}$, respectively.

Commenting on our assignment to the origin of the weak band absorption in the $300-400 \mathrm{~nm}$ region, we notice that the $\mathrm{S}_{0} \rightarrow \mathrm{S}_{3}$ excitation is mainly a HOMO $\rightarrow$ LUMO+1 transition ${ }^{1}\left(\pi, \pi^{*}\right.$-type), thus excluding any sensitivity of this state to variation in solvent polarity. This indeed is found in the absorption spectra of $\mathrm{K} 1$, where the shape of the absorption band at 300-340 nm (assigned to $\mathrm{S}_{3}$ transition) did not change after $\mathrm{MeOH}$ addition to $\mathrm{K} 1$ in $\mathrm{CHX}$ solution. Further evidence is given in the ESP mapped on electron density surface (cf. Fig. S4), where nil contribution is seen on the carbonyl oxygen or the nitrogen groups in the LUMO+1 MOs in nonpolar, as well as polar media. Moreover, our calculations, give the values for the oscillator strengths as $f=0.039, f=0.037$, and $f=0.033$ in $\mathrm{CHX}, \mathrm{ACN}$ and $\mathrm{MeOH}$, respectively. This is in accordance with experimental interpretation of the steady state absorption spectra, where no change in spectral position is seen, rather, the oscillator strength slightly drops in CHX with addition of $\mathrm{MeOH}$ (cf. Figure 1a).

\section{Fluorescence study in solvent mixtures}

\section{Cyclohexane-methanol (CHX-MeOH) system}

Molecules with charge transfer (ICT) character in their excited state, can interact with the surrounding media by many mechanisms, mainly electrostatic and H-bonding [14]. Therefore, solvents capable of donating H-bond can have significant effects on the behavior of molecular systems. Moreover, Hbonding, can preferentially solvate the ICT state affecting the solute's peak position [39] and excited state life-time [40]. Generally, for any binary mixture, the fluorescence maxima are always between the fluorescence peak positions of the molecule in these two pure solvents.

To gain insight into the excited state competitive interaction between the nonpolar CHX and a polar protic solvent such as methanol, we carried out a titration experiment in the $\mathrm{K} 1$ in CHX with different fraction of methanol. This fluorescence titration is displayed in Fig. S5. We noticed enhancement of the emission intensity with small increase in the alcohol fraction in the mixture, apparently due to better solvation of the $\mathrm{S}_{1}$ state by methanol due to higher polarity $\left(\varepsilon_{\mathrm{MeOH}}=\right.$ 32.7 vs. $\varepsilon_{\mathrm{CHX}}=1.88$ ), followed by a decrease in intensity (quenching) as the amount of methanol is increased in the mixture. As evident in Fig. S5, the decrease of the higher energy band between 420 and $470 \mathrm{~nm}$ is accompanied by the appearance and growth of the low-energy band characteristic of emission in neat methanol.

\section{Acetonitrile-methanol (ACN-MeOH) system}

Initially, the presence of a slight amount of methanol in the $\mathrm{MeOH}-\mathrm{ACN}$ mixture of $\mathrm{K} 1$ solution caused immediate quenching of the fluorescence as seen in the sudden drop 
$(>50 \%)$ in the emission band (cf. Fig. S6). Further addition of methanol caused a more steady decrease in emission intensity with considerable broadening of the spectra, and no change in peak position.

This immediate deactivation by the presence of a small amount of methanol in the mixture suggests that the effect is dynamic in nature. This is evident in the $\mathrm{I}_{0} / \mathrm{I}$ vs. [Q] depicted in Fig. S7, which obeys the Stern-Volmer relationship [41], with $R^{2}=0.992$. However, in the $\mathrm{MeOH}-\mathrm{H}_{2} \mathrm{O}$ system the quenching does not follow the simple straight-line equation but rather gives an upward curving plot because of the involvement of quenchers. Moreover, the diminished emission intensity is probably caused by opening some deactivation channel, such as ISC by complexation with the carbonyl motif $[42,43,44]$.

Our TD-DFT calculations show that the $\mathrm{S}_{1} / \mathrm{T}_{1}$ gap in the $\mathrm{K} 1-\mathrm{ACN}$ complex is $0.979 \mathrm{eV}$, and upon attachment of one $\mathrm{MeOH}$ molecules to the K1-ACN (binary K1-ACN-MeOH) (cf. Fig. S3), this energy separation drops slightly to $0.969 \mathrm{eV}$. However, in the $\mathrm{K} 1-\mathrm{MeOH}$ arrangement, this gap slightly decreases further to $0.926 \mathrm{eV}$. Since $\mathrm{S}_{1}$ is ${ }^{1}\left(\pi, \pi^{*}\right)$ in nature and $\mathrm{T}_{1}$ is ${ }^{1}\left(n, \pi^{*}\right)$, it is anticipated that quenching via intersystem crossing (ISC) is a possible channel. Furthermore, we notice that the $\mathrm{S}_{2} / \mathrm{S}_{1}$ energy gap in the K1-ACN configuration is ca. $0.316 \mathrm{eV}$ and becomes $0.395 \mathrm{eV}$ in the $\mathrm{K} 1-\mathrm{ACN}-\mathrm{MeOH}$ arrangement and increases to $0.629 \mathrm{eV}$ in the $\mathrm{K} 1-\mathrm{MeOH}$ complex. These results imply that the likelihood of energy borrowing from higher states diminishes with addition of alcohol molecules to the K1-ACN mixture.

The accepted criteria for a H-bond according to IUPAC definition are, (i) $\mathrm{O} / \mathrm{N} \cdots \mathrm{H}$ distance should be $<2.650 \AA$, (ii) $\mathrm{O} / \mathrm{N} \cdots \mathrm{H}$ angle is $>120^{\circ}$. The B3LYP optimized minimum structure of the $\mathrm{K} 1-\mathrm{ACN}-\mathrm{MeOH}$ system shows that the $\mathrm{C}=\mathrm{O} \cdots \mathrm{H}-\left(\mathrm{CH}_{2}-\mathrm{CN}\right)$ distance is $2.223 \AA$, and the $\mathrm{C}=\mathrm{O} \cdots \mathrm{H}-$ $\mathrm{C}$ angle is $156.373^{\circ}$, indicating the occurrence of $\mathrm{H}$-bonding. This structure is further stabilized by another H-bond between the solute nitrogen $\left(\mathrm{N}_{39}\right)$ (cf. Fig. S3) and the phenyl hydrogen N39 $\cdots$ H24-ph, with a distance ca. $2.611 \AA$ and a H-bond angle of ca. $171.237^{\circ}$.

In the $\mathrm{K} 1-\mathrm{MeOH}$ complex, the $\mathrm{H}-$ bond is established strongly as the calculated $\mathrm{C}=\mathrm{O} \cdots \mathrm{H} 34-\mathrm{O} 42$ distance is shortened to $1.849 \AA$ and the angle becomes $172.372^{\circ}$. On the other hand, the solvent's oxygen is involved in forming another $\mathrm{H}$ bond with the central alkene-hydrogen (H34), ca. distance of $2.384 \AA$ and angle of $131.938 \AA$. Our interpretation for the stronger H-bond in $\mathrm{K} 1-\mathrm{MeOH}$ structure, compared to the K1$\mathrm{ACN}$ system, is due to better solvation of the structure through charge migration from the $\mathrm{C}=\mathrm{O}$ oxygen lone-pair. Our NBO calculations (as indicated earlier), revealed that the two $\mathrm{O} 16$ lone-pairs, $\operatorname{lp}(1)$ and $\operatorname{lp}(2)$ transfer $16.71 \mathrm{kcal} \mathrm{mol}^{-1}$ and $18.23 \mathrm{kcal} \mathrm{mol}^{-1}$ to $\sigma^{*}(\mathrm{H} 37-\mathrm{O} 42)$ in the $\mathrm{K} 1-\mathrm{MeOH}$ complex, respectively, whereas this stability is only $3.80 \mathrm{kcal} \mathrm{mol}^{-1}$ from $\operatorname{lp}(1) \mathrm{O} 16$ to $\sigma^{*}(\mathrm{H}-\mathrm{C})$ in the $\mathrm{K} 1-\mathrm{ACN}$ system. This is a clear indication that $\mathrm{MeOH}$ becomes better bound to the $\mathrm{C}=\mathrm{O}$ motif, and the charge migration will facilitate better energy quenching of the excited state due to better stabilization of the structure.

Moreover, we also notice that in the K1-ACN-MeOH binary arrangement, in comparison to $\mathrm{K} 1-\mathrm{ACN}$ and $\mathrm{K} 1-\mathrm{MeOH}$, attachment of one $\mathrm{MeOH}$ increases the strength between $\mathrm{ACN}$ and the carbonyl $\left(\mathrm{C}=\mathrm{O} \cdots \mathrm{H}-\mathrm{CH}_{2}-\mathrm{CN}-\mathrm{MeOH}, d=2.1919 \AA\right)$ compared to $\mathrm{C}=\mathrm{O} \cdots \mathrm{H}-\mathrm{CH}_{2}-\mathrm{CN}(d=2.223 \AA)$. Furthermore, the stabilization energy $\left(E^{2}(\mathrm{i}, \mathrm{j})\right)$ from $\mathrm{C}=\mathrm{O} 16$ to $\sigma^{*}\left(\mathrm{H}-\mathrm{CH}_{2}-\right.$ $\mathrm{CN}$ ) increases slightly from $3.80 \mathrm{kcal} \mathrm{mol}^{-1}$ (K1-ACN) to $3.84 \mathrm{kcal} \mathrm{mol}^{-1}$ (K1-ACN-MeOH), respectively (cf. Figure S3). H-bonding angle also increases from $148.681^{\circ}$ to $156.373^{\circ}$ in the binary arrangement due to stronger stabilization.

Furthermore, we find that in the calculated K1-ACN$\mathrm{MeOH}$ system, there is a huge energy stabilization from acetonitrile nitrogen $\left(\mathrm{CH}_{3}-\mathrm{C} \equiv \mathrm{N} 38\right)$ to the $\sigma^{*}(\mathrm{H} 45-\mathrm{O} 44)$ of the $\mathrm{MeOH}$ (ca. $10.86 \mathrm{kcal} \mathrm{mol}^{-1}$ ), with almost no change in stabilization from $\mathrm{C}=\mathrm{O}$ lone-pair to the bonded $\mathrm{H} 42-\mathrm{C} 40$ of acetonitrile (ca. 3.84 and $2.05 \mathrm{kcal} \mathrm{mol}^{-1}$, from $\mathrm{lp}(1)$ and $\mathrm{lp}(2)$ lone pairs, respectively). Careful analysis of Fig. S3 reveals that attachment of a single $\mathrm{MeOH}$ molecule to the $\mathrm{K} 1-$ ACN cluster, creates a strong H-bond between N38 of ACN and $\mathrm{H} 45$ of $\mathrm{MeOH}\left(d_{\mathrm{N} \ldots \mathrm{H}}=2.0440 \AA\right)$, with H-bond angle of ca. $174.857^{\circ}$. These findings indicate establishment of cooperative charge migration from $\mathrm{ACN}$ to $\mathrm{MeOH}$ and explains the sudden quenching with the initial small addition of $\mathrm{MeOH}$ to the existing ACN micro-solvated K1.

We also calculated the interaction energies for the K1-solvent(s) arrangement using the following equation:

$E_{i}=E_{\mathrm{K} 1-\mathrm{solv}}-E_{\mathrm{K} 1}-E_{\mathrm{sol}}$

where $E_{\mathrm{K} 1 \text {-solv }}$, is the ground state minimum energy for the solute-solvent(s) complexes, whereas $E_{\mathrm{K} 1}$ and $E_{\mathrm{sol}}$, were taken as single-point energies for the unrelaxed individual solute or solvent(s) in the complex without the solvent(s) or the solute, respectively. The results for the interaction energies support the NBO analysis, and these results are depicted in Fig. S8.

The calculated $E_{\mathrm{i}}$ were between -5.4 and $-8.2 \mathrm{kcal} \mathrm{mol}^{-1}$ for the K1-solvent complexes and between -9.7 and $-34.8 \mathrm{kcal} \mathrm{mol}^{-1}$ for the binary $\mathrm{K} 1$-solvent $1-\mathrm{solv}_{2}$ arrangements. Thus, the interaction energy is more favored in the case of binary systems involving methanol.

The steady quenching of the fluorescence with increase in alcohol ratio in the measured emission spectra is thus explained on the basis that complete H-bonding of alcohol molecules with $\mathrm{C}=\mathrm{O}$ promotes further radiationless deactivation. As we indicated earlier the $S_{1} / T_{1}$ gap in these arrangements decreases in the order: K1-ACN $(0.9795 \mathrm{eV}>\mathrm{K} 1-\mathrm{ACN}$ - 
MeOH $(0.9690 \mathrm{eV}>\mathrm{K} 1-\mathrm{MeOH}(0.9262 \mathrm{eV}$ ) (cf. Table 3). Therefore, $\mathrm{C}=\mathrm{O} \cdots \mathrm{MeOH}$ inter-molecular H-bond decreases the $S_{1} / T_{1}$ energy separation and thus opens up a radiationless channel.

\section{Methanol- $\mathrm{H}_{2} \mathrm{O}$ binary system}

Addition of $\mathrm{H}_{2} \mathrm{O}$ to a solution of $\mathrm{K} 1$ in $\mathrm{MeOH}$ caused the emission intensity to decrease steadily, with peak shift to lower energy and broadening of the spectrum (cf. Fig. S9). To explain this phenomenon, we also carried out NBO calculations on the $\mathrm{K} 1-\mathrm{MeOH}-\mathrm{H}_{2} \mathrm{O}$ complexation.

In this regard, our NBO analysis of the $\mathrm{K} 1-\mathrm{MeOH}, \mathrm{K} 1-$ $\mathrm{MeOH}-\mathrm{H}_{2} \mathrm{O}$, and $\mathrm{K} 1-\mathrm{H}_{2} \mathrm{O}$ configurations showed a decrease in the amount of charge-transfer for $\operatorname{lp}(1) n_{\mathrm{C}=\mathrm{O}}$ and $\operatorname{lp}(2) n_{\mathrm{C}=\mathrm{O}}$ (K1) to $\sigma^{*} \mathrm{H} 37-\mathrm{O} 42(\mathrm{MeOH})$ (cf. Fig. S3) from 16.71 and $18.23 \mathrm{kcal} \mathrm{mol}^{-1}$ in the $\mathrm{K} 1-\mathrm{MeOH}$ complex to 11.20 and $4.15 \mathrm{kcal} \mathrm{mol}^{-1}$ in the $\mathrm{K} 1-\mathrm{MeOH}-\mathrm{H}_{2} \mathrm{O}$ binary, respectively. Furthermore, we noticed an increase in the $\mathrm{C}=\mathrm{O}$...H-O Hbond distance from $1.84966 \AA$ to $1.85229 \AA$, when one $\mathrm{H}_{2} \mathrm{O}$ molecule is attached to the $\mathrm{MeOH}-\mathrm{K} 1$ complex.

In the $\mathrm{K} 1-\mathrm{H}_{2} \mathrm{O}$ configuration, the charge contribution of the two 016 lone-pairs becomes ca. $7.417 \mathrm{k} \mathrm{cal} \mathrm{mol}^{-1}$ and $9.38 \mathrm{k} \mathrm{cal} \mathrm{mol}^{-1}$, respectively. The solvent forms a second $\mathrm{H}$-bond with the $\mathrm{K} 1-\mathrm{C} 17-\mathrm{H} 43$ and transfers $\sim 0.05$ $\mathrm{kcal} \mathrm{mol}^{-1}$ to the molecule's $\mathrm{C} 17-\mathrm{H} 43$ (in $\mathrm{K} 1-\mathrm{MeOH}$ ) and from water's $\mathrm{O} 38$ ca. $2.10 \mathrm{mkcal} \mathrm{ol}^{-1}$ (in $\mathrm{K} 1-\mathrm{MeOH}-\mathrm{H}_{2} \mathrm{O}$ ) and ca. $1.48 \mathrm{kcal} \mathrm{mol}^{-1}$ from $\mathrm{H}_{2} \mathrm{O} 38$ in the $\mathrm{K} 1-\mathrm{H}_{2} \mathrm{O}$ arrangement.

We notice that in the $\mathrm{K} 1-\mathrm{MeOH}-\mathrm{H}_{2} \mathrm{O}$ complex there is a considerable charge-transfer (ca. $17.45 \mathrm{kcal} \mathrm{mol}^{-1}$ ) from methanol's $\mathrm{O} 41$ to the $\sigma^{*} \mathrm{O} 38-\mathrm{H} 40$ of the water molecule. This is reflected in the overall interaction energy of this complex ca. $34.8 \mathrm{kcal} \mathrm{mol}^{-1}$ (cf. Fig. S8). Moreover, the addition of water to the $\mathrm{K} 1-\mathrm{MeOH}$ complex decreases the $\mathrm{S}_{2} / \mathrm{S}_{1}$ gap from $0.6289 \mathrm{eV}(\mathrm{K} 1-\mathrm{MeOH})$ to $0.5225 \mathrm{eV}\left(\mathrm{K} 1-\mathrm{MeOH}-\mathrm{H}_{2} \mathrm{O}\right)$, and this gap further shrinks to $0.391 \mathrm{eV}$ in the $\mathrm{K} 1-\mathrm{H}_{2} \mathrm{O}$ complex (cf. Table 3).

Thus, it appears that the initial addition of water weakens the already established $\mathrm{H}$-bond. However, the H-bond between $\mathrm{K} 1$ and $\mathrm{H}_{2} \mathrm{O}$ in $\mathrm{K} 1-\mathrm{H}_{2} \mathrm{O}$ is comparable to the one in $\mathrm{K} 1-\mathrm{MeOH}$ (compare $d_{\mathrm{O} . . . \mathrm{H}}=1.8496 \AA$ vs $1.8491 \AA$ and $\mathrm{C} 11-$ O16-H37 angle of $131.938^{\circ}$ vs. $171.071^{\circ}$ for the $\mathrm{K} 1-\mathrm{MeOH}$ and $\mathrm{K} 1-\mathrm{H}_{2} \mathrm{O}$, respectively). Once again, similar interaction energies were found (cf. Fig. S8). However, the emission in $\mathrm{H}_{2} \mathrm{O}$ becomes weaker (more quenching) compared to $\mathrm{MeOH}$. We believe that in the $\mathrm{K} 1-\mathrm{H}_{2} \mathrm{O}$ case, crossing from $\mathrm{S}_{1}{ }^{1}\left(\pi, \pi^{*}\right.$; bright) to the $\mathrm{S}_{2}{ }^{1}\left(n, \pi^{*}\right.$; dark) is responsible for this weak emission because a direct impact of low $\mathrm{S}_{2} / \mathrm{S}_{1}$ gap (ca. $0.391 \mathrm{eV}$ ) facilitates this crossing. Interestingly, the $\mathrm{S}_{3} / \mathrm{S}_{1}$ separation is found to be the lowest in the case of solvation by pure $\mathrm{H}_{2} \mathrm{O}$ or as a co-solvent.

\section{Conclusions}

Compound K1 of the type D-A cycloalkanone studied here, shows strong fluorescence emission in nonpolar as well as in polar aprotic solvents. However, in polar protic media, emission is weak. The emission of compound K1 in neat acetonitrile is highly quenched in the presence of small amounts of protic solvent, such as methanol. Furthermore, emission intensity of the binary system is dramatically decreased in the presence of water in the mixture.

Quantum chemical calculations, based on DFT and NBO, were performed for identification of $\mathrm{C}=\mathrm{O} \ldots \mathrm{HO}$ and $-\mathrm{CN}$... $\mathrm{HO}$ H-bond interactions in the K1-solvent(s) system(s) and elucidate the strength of these interactions.

The calculated data of the modeled K1-solvent ${ }_{1}$ and K1solvent $_{2}$ or the binary K1-solvent 1 -solv 2 configurations confirm involvement of inter-molecular H-bonding with the carbonyl $\mathrm{C}=\mathrm{O}$ motif in the fate of the emission (quenching). These close encounters facilitate the intersystem crossing (ISC) process by reducing the $S_{1} / T_{1}$ energy gap, which opens a deactivation channel. The weak fluorescence in methanol becomes much weaker (quenched) in water. The explanation is that the later solvent enhances another deactivation pathway through internal conversion between $S_{1}$ (bright) state and $S_{2}$ (dark) state due to the proximity of these states.

Funding Information Open Access funding provided by the Qatar National Library.

\section{Compliance with ethical standards}

Competing interests The authors declare that they have no competing interests.

Open Access This article is distributed under the terms of the Creative Commons Attribution 4.0 International License (http:// creativecommons.org/licenses/by/4.0/), which permits unrestricted use, distribution, and reproduction in any medium, provided you give appropriate credit to the original author(s) and the source, provide a link to the Creative Commons license, and indicate if changes were made.

\section{References}

1. Bures F (2014) Fundamental aspects of property tuning in push-pull molecules. RSC Adv 4:58826

2. Anto RJ, Sukumavana K, Kuttana G, Raob MNA, Subbarajue V, Kuttana R (1995) Anticancer and antioxidant activity of synthetic chalcones and related compounds. Cancer Lett 97:33

3. Herevicia F, Ferrandiz MI, Ubeda A, Dominguez JN, Charris JE, Lobo GM, Alcaraz MJ (1998) Synthesis and anti-inflammatory activity of chalcone derivatives. Bioorg Med Chem Lett 8:1169

4. Wu JH, Wang XH, Yi YH (2003) Anti-AIDS agents 54. A potent anti-HIV chalcone and flavonoids from genus Desmos. Biorg Med Chem Lett 13:1813

5. Liu M, Wilairat P, Go MI (2001) Antimalarial Alkoxylated and hydroxylated Chalones: structure-activity relationship analysis. J Med Chem 44:4443 
6. Sarojinia BK, Narayanab B, Ashalathab BV, Indirac J, KLobo KG (2006) Synthesis, crystal growth and studies on non-linear optical property of new chalcones. J Cryst Growth 295: 54

7. Shettigar S, Chandrasekharan K, Umesh G, Sarojini BK, Narayana B (2006) Studies on nonlinear optical parameters of bis-chalcone derivatives doped polymer. Polymer 47:3565

8. Patila PS, Dharmaprakash SM, Funb HK, Karthikeyan MS (2006) Synthesis, growth, and characterization of 4-OCH3-4'Nitrochalcone single crystal: a potential NLO material. J Cryst Growth 297:111

9. Ravindra HJ, Chandaraskharan K, Harrison WTA, Dharamaprakash SM (2009) Structure and NLO property relationship in a novel chalcone co-crystal. Appl Phys B Lasers Opt 94:503

10. Fried SD, Bagchi S, Boxer SG (2013) Measuring electrostatic fields in both hydrogen bonding and non-hydrogen bonding environments using carbonyl vibrational probes. J Am Chem Soc 135(30):11181-11192

11. Zhao G-J, Han K-L (2009) Role of intramolecular and intermolecular hydrogen bonding in both singlet and triplet excited states of Aminofluorenones on internal conversion, intersystem crossing, and twisted intramolecular charge transfer. J Phys Chem A 113(52):14329-14335

12. Bautista JA, Connors RE, Raju BB, Hiller RG, Sharples FP, Gosztola D, Wasielewski MR, Frank HA (1999) Excited state properties of Peridinin: observation of a solvent dependence of the lowest excited singlet state lifetime and spectral behavior unique among carotenoids. J Phys Chem B 103:8751-8758

13. Irene CM, Kwan XM, Gang W (2007) Probing hydrogen bonding and ion-carbonyl interactions by solid- spectroscopy: G-ribbon and G-quartet. J Am Chem Soc 129:2398-2407

14. Haldar T, Bagchi S (2016a) Electrostatic interaction are key to $\mathrm{C}=\mathrm{O}$ $n-\pi^{*}$ shifts: an experimental proof. J. Phys. Lett. 7:2270-2275

15. Patrick G. (2017) An Introduction to Medicinal Chemistry, 6th edn. Oxford University Press, Oxford

16. Stefanisinova M, Tomekova V, Kozurkova M, Ostro A, Marekova M (2011) Study of DNA interaction with cyclic Chalcone derivatives by Spectroscpic techniques. Spectrochim. Acta A 81:666-671

17. Yang X, Shen G, Yu R (1999) Microchem J 62:394-404

18. Al-Ansari IAZ (2016) Physicochemical properties of derivatives of $N, N$-Dimethylamino-cyclic-chalcones: experimental and theoretical study. Chemistry Select 1:2935-2944

19. Marcus Y (2002) Solvent mixtures: properties and selective solvation. CRC, Boca Raton

20. Becke AD (1993) Density-functional thermochemistry. III. The role of exact exchange. J Chem Phys 98:5648

21. Lee C, Yang W, Parr RG (1988) Development of the Colle-Salvetti correlation-energy formula into a functional of the electron density. Phys Rev B 37:785

22. Ditchfield R, Hehre W, Pople J (1971) Self-Consistant molecularorbital methods. IX. An extended Gaussian type basis for molecular orbital studies of organic molecules. J Chem Phys 54:724-728

23. Jennifer MR, Jennifer MH, William AM, Robert CC, Erin S, Diego T, Amandra JM (2017). J Photochem Photobiol A: Chem 337:207-215

24. Sheng Y, Leszczynski J, Garacia A, Rosario R, Gust D, Springer J (2004) J Phys Chem B 108:16233-16243

25. Holmen A, Broo A (1995) Int J Quantum Chem 22:113-122
26. Lange AW, Herbert JM (2010) Polarizable continuum reaction-field solvation models affording smooth potential energy surfaces. J Phys Chem Lett 1:556-561

27. Casida ME (1995) In: Chong DP (ed.) Recent Advances in Computational Chemistry, vol 1. World Scientific, Singapore

28. Reed AE, Curtiss LA, Weinhold F (1988) Intermolecular 577 interactions from a natural bond orbital, donor-acceptor viewpoint. Chem Rev 88:899-926

29. Weinhold F (1998) Encyclopedia of computational chemistry. In: Rague-Schleyer PV, Allinger NL, Kollman PA, Clark T, Schaefer III HF, Gasteiger J, Schreiner PR (eds), vol 3. Wiley, Chichester, pp 1792-1811

30. Weinhold F, Landis CR (2001) Chem Educ Res Pract Eur 2:91-104

31. Weinhold F, Landis CR (2005) Valency and bonding: a natural bond orbital donor-acceptor perspective. Cambridge University Press, New York

32. Glendening DE, Badenhoop JK, Reed AE, Carpenter J, Bohmann JA, Morales CM, Landis CR, Weinhold F (2013) NBO-6. Theoretical chemistry institute, University of Wisconsin, Madison

33. Frisch M, Trucks G, Schlegel H, Scuseria G, Robb M, Cheeseman J, Scalmani G, Barone V, Petersson GJ, et al (2016) Gaussian 16, revision A.03. Gaussian Inc., Wallingford

34. Dennington R, Keith TA, aMillam JM (2016) GaussView, Version 6. Semichem Inc., Shawnee Mission

35. van Duijnen PT, de Vries AH (1996) Direct reaction fields forces: a consistent way to connect and combine quantum chemical and classical descriptions of molecules. Int J Quantum Chem 60:1111-1132

36. Haldar T, Bagchi $\mathrm{S}$ (2016b) Electrostatic interactions are key to $\mathrm{C}=\mathrm{O} n-\pi^{*}$ shifts: an experimental proof. J Phys Chem Lett 7: 2270-2275

37. Ito M, Inuzuka K, Imanishi S (1960) Effect of solvent on $n$, absorption spectra of ketones. J Am Chem Soc 82:1317-1322

38. Mc Rae EG (1957) Theory of solvents on molecular electronic spectra-frequency shifts. J Phys Chem 61:562-572

39. Brealey GJ, Kasha M (1955) The role of hydrogen bonding in the $n \rightarrow \pi^{*}$ blue-shift phenomenon. J Am Chem Soc 77:4462-4468

40. Hirai S, Banno M, Ohta K, Palit DK, Tominaga KK (2007) Vibrational dynamics of the $\mathrm{CO}$ stretching mode of 9-fluorenone in alcohol solution. Chem Phys Lett 450:44

41. Lakowicz JR (2006) Principles of fluorescence spectroscopy, 3rd edn. Springer, New York, p 954

42. Alty IG, Abelt CJ (2017) Steroelectronic of the hydrogen-bond induced quenching of 3-Aminofluorenones. J Phys Chem A 121: $5110-5115$

43. Green AM, Anelt CJ (2015) Dual-sensor fluorescent probes of surfactant-induced unfolding of human serum albumin. J Phys Chem B 119:3912-3919

44. Nikitina YY, Iqbal ES, Yoon HJ, Abelt CJ (2013) Preferential solvation in carbonyl-twisted PRODAN derivatives. J Phys Chem A 117:9189-9195

Publisher's note Springer Nature remains neutral with regard to jurisdictional claims in published maps and institutional affiliations. 